\title{
Pedagogia Reggio Emilia no Brasil e o Projeto Político Pedagógico
}

Reggio Emilia Pedagogy in Brazil and the Political Pedagogical Project

\author{
Luiz Eduardo Pacagnella ${ }^{1}$, Tatiane da Silva ${ }^{2 *}$
}

\begin{abstract}
${ }^{1}$ Graduado em Licenciatura em Educação Física - Universidade Estadual de Campinas (UNICAMP) e Ciências do Desporto e Educação Física - Universidade de Coimbra (UC) - Faculdade de Educação Física. Avenida Érico Veríssimo, 701, Cidade Universitária Zeferino Vaz, Barão Geraldo - $13.083-851$ - Campinas, SP - Brasil

${ }^{2 *}$ Doutora em Educação Escolar - Universidade Estadual Paulista "Júlio de Mesquita Filho (UNESP) - Faculdade de Ciências e Letras de Araraquara. Rodovia AraraquaraJaú - Km 1 - 14800-901 - Araraquara, SP - Brasil <tathisilva@hotmail.com>
\end{abstract}

\section{Resumo}

Pensando na complexidade e singularidade dos conceitos que determinada concepção pedagógica implica, na sua importância e relevância para a compreensão do processo de ensino e nas possíveis contribuições para a discussão educacional, esse trabalho pretendeu analisar e identificar as principais percepções de professores e gestores a respeito do processo de implementação da concepção pedagógica de Reggio Emilia no Projeto Político Pedagógico de uma instituição particular de ensino brasileira. Como metodologia utilizada realizouse revisão bibliográfica, juntamente com aplicação de questionários envolvendo professores (pedagogos); professores especialistas (Artes, Educação Física, Expressão Corporal, Música); gestores pedagógicos (coordenadores) e gestores administrativos. Somado a isso, foram realizadas observações diretas do ambiente escolar na escola lócus da pesquisa. A partir das respostas obtidas, verificou-se que apesar da proposta reggiana em seus pressupostos originais preconizar uma educação baseada no espírito coletivo de colaboração entre comunidade escolar, famílias e alunos, pôde-se verificar na análise do caso brasileiro que as decisões e ações para a implementação da abordagem reggiana não ocorreram de forma coletiva, mas sim de forma centralizadora, tendo como núcleo os gestores pedagógicos e administrativos, não havendo a participação da comunidade escolar. Tal fato se evidencia como uma das principais causas da dificuldade de implementação de maneira efetiva da proposta reggiana na instituição pesquisada e da efetivação de um Projeto Político Pedagógico com uma abordagem educativa diferenciada.

Palavras-chave: abordagem reggiana no Brasil, concepção pedagógica de Reggio Emilia, educação básica, organização do trabalho escolar

\begin{abstract}
Based on concerns about the current teaching process, this research project aims to analyze and identify the main perceptions of teachers and managers regarding the process of implementation of the pedagogical conception of Reggio Emilia in the Pedagogical Political Project of a private educational institution. As methodology, a bibliographical survey was carried out and questionnaires were applied involving teachers (pedagogues); Specialist teachers (Arts, Physical Education, Body Expression, Music); pedagogical managers (coordinators) and administrative managers. In addition, direct observations of the school environment were conducted at the research school. From the answers obtained, it was verified that the decisions and actions for the implementation of the reggiana approach, do not occur in a collective way, but in a centralized way, having as the core the pedagogical and administrative managers, without the participation of the school community. This fact can be evidenced as one of the main causes of the difficulty of effectively implementing the reggiana proposal in the researched institution.
\end{abstract}

Keywords: reggiana proposal in Brazil, pedagogical conception of Reggio Emilia, basic education, school work organization

\section{Introdução}

Atualmente, o âmbito educacional é composto por diversas abordagens pedagógicas, que se definem e se diferenciam a partir da concepção que possuem acerca dos métodos utilizados no processo de ensino e dos conceitos que estabelecem para definir e compreender o papel dos sujeitos que estão imersos na relação pedagógica. Entende-se por abordagem pedagógica as concepções educacionais que postulam determinados conceitos e métodos de ensino a serem aplicados em busca da aprendizagem do aluno. De acordo com Mizukami (1986), algumas dessas pedagogias apresentam um claro referencial filosófico e psicológico. Entretanto, uma boa parte dessas pedagogias são exclusivamente fundamentadas na prática e na imitação de modelos fechados e pré-determinados, eximindo-se assim das reflexões teóricas sobre o processo de ensino e sobre os elementos que o compõe, assim como sobre o contexto 
no qual essas pedagogias serão implantadas. Para que o processo educacional não seja tratado de forma simples e reducionista, a complexidade da realidade educacional deve ser levada em consideração, juntamente com as reflexões teóricas que discutem os elementos que integram essa realidade, pois o conhecimento humano, elemento fundamental desse processo, dependendo dos diferentes referenciais, pode ser explicado de maneiras variadas, tendo por base conceitos diversos de homem, mundo, cultura, sociedade, educação, etc.

Pensando na complexidade e singularidade dos conceitos que determinada concepção pedagógica implica, na sua importância e relevância para a compreensão do processo de ensino e nas possíveis contribuições para a discussão educacional, tomamse como objeto de análise a Pedagogia Reggio Emilia. Criada pelo pedagogo e educador Loris Malaguzzi, a Pedagogia Reggio Emilia carrega consigo o nome da região da Itália onde foi desenvolvida. No ano de 1946, logo após o término da Segunda Guerra Mundial, no Vilarejo de Vila Cella, a população viu como necessário a construção de uma escola para crianças pequenas. A escola foi erguida por intermédio da venda de um tanque de guerra, seis cavalos e três caminhões, deixados pelos alemães em decorrência da guerra, num movimento que envolveu toda a comunidade, em especial os pais das crianças (Latalisa, 2010).

O projeto de Malaguzzi teve por influência teorias psicopedagógicas da Europa, tais como a proposta por Jean Piaget e Lev Vygotsky, assim como inspirou-se nas propostas pedagógicas do filósofo norte-americano John Dewey. A partir dessas abordagens pedagógicas, a proposta reggiana institui os pilares de uma pedagogia centrada no desenvolvimento integral das crianças, abarcando os aspectos intelectual, emocional, social e moral (Conti, 2018).

A partir dessa iniciativa, novas escolas foram construídas, apresentando como base principal o sentido de coletividade e união, uma vez que eram operadas pela comunidade, tendo suporte do Comitê Nacional para Libertação. Os professores que ministravam as aulas nessas escolas eram formados por meio de escolas católicas, sendo muito receptivos à ideia de ensinar as crianças enquanto eles mesmos aprendiam. Buscavase com essa postura que o educador aprendesse com a criança, ou seja, uma vez pautado na sua compreensão, mediante observação, sobre a lógica de aprendizagem do educando, o educador começava a pensar alternativas eficientes para ajudar a criança a continuar aprendendo, dando ênfase maior no conhecimento possuído e construído pelo educando (Latalisa, 2010).

Tomando como base esses pressupostos, a abordagem Reggio Emilia propõe a educação como algo a ser repensado e reconstruído constantemente, apresentando a criança como centro do processo educativo e considerando como base sólida para a formação do indivíduo a interação entre o sistema de escolarização, a família e a comunidade, sendo essa uma interação integrada e participativa.

Diferenciando-se das abordagens pedagógicas tradicionais, as quais privilegiam um método préestabelecido de ensino e nas quais a verticalidade do processo de aprendizado (adulto-criança) é predominante, a abordagem reggiana estabelece que os educadores tenham por premissa a observação e escuta dos alunos, buscando-se assim trabalhar em cima de suas potencialidades individuais e ao mesmo tempo coletivas (Conti, 2018). Nessa direção, as atividades pedagógicas se desenvolvem por meio de projetos, os quais não são antecipadamente planejados pelos professores, surgindo por intermédio das ideias que provém das relações sociais dos próprios alunos e desenvolvidas por meio de diferentes linguagens.

Esses projetos são desenvolvidos em laboratórios criados nas escolas reggianas onde os pequenos vão trabalhar diferentes linguagens, tais como as gráficas e de manipulação (maquetes), as relacionadas ao corpo (que dizem respeito aos movimentos) as relativas a comunicação verbal e a comunicação não-verbal, o pensamento lógico, discussões éticas, entre outras. O educador atua a partir das experiências obtidas por meio da pesquisa e das descobertas sensoriais das crianças, de maneira a desenvolver neles a autonomia, a qual será base para o aprimoramento e desenvolvimento de suas habilidades; nesse contexto, o espaço no qual as atividades acontecem é primordial, considerado por Malaguzzi, como um educador (Conti, 2018).

Considerando a singularidade da proposta reggiana, a pesquisa aqui apresentada tomou como elemento de análise uma escola particular brasileira que adotou em seu Projeto Político Pedagógico [PPP] a concepção de educação desenvolvida por Malaguzzi.

O PPP apresenta-se como um documento primordial da escola, que orienta e guia as atividades desenvolvidas no ambiente escolar tendo como finalidade a transformação e a modificação desse ambiente. Construir um PPP requer primeiramente, autonomia por parte da escola para desenvolver sua capacidade de delinear, por meio desse documento, sua própria identidade (Veiga, 2004). A criação dessa identidade implica, necessariamente, a participação de todos os agentes envolvidos no processo educacional de determinada instituição de ensino na elaboração do PPP. Uma vez que o "eu” precisa ser substituído pelo "nós", o processo de construção desse documento não deve ser encarado como algo rápido e simples. Para que a participação não seja mera teoria, o grupo precisa ter claro seus ideais de educação e permanecer unido, desde 
o início desse processo, superando as dificuldades que surgirão durante todo o seu desenvolvimento e posterior aplicação (Ferrari, 2011).

Considerando essas reflexões, o objetivo central da pesquisa baseou-se em analisar e identificar as principais percepções de professores e gestores a respeito do processo de implementação da concepção pedagógica de Reggio Emilia no PPP de uma instituição particular brasileira. Ao mesmo tempo, buscou-se verificar, por intermédio da fala dos respondentes, o nível de participação dos atores educacionais e da comunidade no processo de elaboração do novo PPP, bem como refletir sobre a importância da participação de toda a comunidade escolar na construção desse projeto.

\section{Material e Métodos}

A pesquisa insere-se no âmbito da abordagem qualitativa. Para Godoy (Neves, 1996), os trabalhos qualitativos apresentam um conjunto de características fundamentais, dentre as quais podemos destacar o ambiente natural como fonte direta de dados e o reconhecimento do pesquisador como instrumento fundamental; além do seu caráter descritivo e a preocupação com o significado que as pessoas dão às coisas e à sua vida.

As pesquisas qualitativas apresentam diversas técnicas interpretativas que visam descrever, analisar e decifrar as partes de um sistema complexo de interpretações. Desse modo ao tomar como objetivo traduzir e expressar o sentido dos fenômenos do mundo social, a abordagem qualitativa busca diminuir a distância entre teoria e dados e entre contexto e ação (Maanen, 1979). Neves (1996) ressalta que em sua maioria, os estudos qualitativos são feitos no local de origem dos dados, o que não impede o pesquisador de empregar a lógica do empirismo científico (adequada para fenômenos claramente definidos), mas partem da suposição de que seja mais apropriado empregar a perspectiva da análise fenomenológica, quando se trata de fenômenos singulares e dotados de certo grau de ambiguidade.

Considerando os apontamentos dos autores supracitados, a pesquisa realizou, para consecução dos objetivos a que se propôs, um levantamento e análise de material bibliográfico utilizado para fundamentar suas reflexões e discussões. Dentre os autores estudados, especialmente sobre a abordagem pedagógica de Reggio Emilia, destacamos os trabalhos de Malaguzzi (1999), Rinaldi (1999) e Latalisa (2010). Com relação às reflexões acerca do Projeto Politico Pedagógico (PPP) e da participação da comunidade escolar, bem como a influência das características dos atores educacionais, utilizou-se Nóvoa (1992), Lima (2002), Veiga (2004) e Ferrari (2011). Por fim, para dialogar sobre a metodologia de pesquisa qualitativa utilizada, levaram-se em consideração as reflexões provenientes de Maanen (1979), Godoy (1995), Neves (1996), Alves-Mazzotti (2006).

Além do levantamento bibliográfico, realizouse a aplicação de questionários envolvendo parte da comunidade escolar que atua diretamente com a abordagem pedagógica de Reggio Emilia. A amostra constituída por 14 participantes foi composta por professores (pedagogos); professores especialistas (Artes, Educação Física, Expressão Corporal, Música); gestores pedagógicos (coordenadores) e gestores administrativos. Somado a isso, foram realizadas observações diretas do ambiente escolar na escola lócus da pesquisa.

A pesquisa foi aplicada durante o mês de Março de 2017, por intermédio da ferramenta Documentos Google ${ }^{1}$. A escolha da ferramenta deu-se primeiramente pelos fatores de acessibilidade e praticidade, uma vez que todos os envolvidos estavam familiarizados com esse instrumento de coleta por o utilizarem em seu ambiente de trabalho. Além do fato de que essa ferramenta garante a possibilidade do anonimato, uma vez que uma das metas da pesquisa era recolher informações sem que os participantes se sentissem coagidos de forma alguma.

O questionário utilizado contou com 11 perguntas. As perguntas do intervalo de 1 a 5 e de 9 a 11 eram destinadas a professores, gestores pedagógicos e gestores administrativos. As perguntas que compreendem $O$ intervalo de 6 a 8 eram destinadas apenas a gestores pedagógicos e gestores administrativos.

O questionário apresentou como estrutura os seguintes elementos: termo de consentimento livre e esclarecido, o qual garantiu ao participante que todos os seus direitos fossem respeitados, trazendo também de modo claro e compreensível os objetivos da pesquisa. Perguntas de 1 a 4, compostas de questões fechadas de caráter pessoal, tendo por objetivo identificar idade, formação acadêmica, cargo ocupado na instituição e tempo que ocupa o referido cargo de maneira a permitir a caracterização do perfil do respondente. Perguntas de 5 a 11, constituídas por questões abertas que visavam copilar informações a respeito das abordagens pedagógicas trabalhadas anteriormente pelos participantes; identificar o processo de implementação da abordagem de Reggio Emilia e se houve participação de toda a comunidade escolar na construção do projeto; a aceitação do corpo docente e comunidade em relação à implementação da abordagem; o processo de implementação da abordagem de Reggio Emilia nas atividades pedagógicas diárias; a visão dos profissionais com relação à eficácia da proposta no PPP e os fatores que poderiam auxiliar um maior

${ }^{1} \mathrm{O}$ questionário pode ser acessado pelo link: https://goo.gl/forms/XUQLNY1bGUlwKSIh2 ou requerido por intermédio de solicitação enviada ao endereço eletrônico do responsável pela pesquisa 
envolvimento e aplicabilidade da abordagem.

A instituição privada de ensino analisada se localiza no interior do Estado de São Paulo, sendo seus alunos provenientes da cidade sede e de regiões vizinhas. $\mathrm{O}$ colégio atende cerca de mil alunos, com idades entre dois a dezoito anos, distribuído entre as seguintes modalidades de ensino: Educação Infantil, Ensino Fundamental e Médio.

\section{Resultados e Discussão}

$\mathrm{Na}$ pesquisa realizada foram analisadas as respostas de 14 participantes distribuídos nas seguintes faixas etárias: 5 participantes responderam que se situavam na faixa de idade entre 23 a 30 anos; 5 respondentes indicaram o interregno de 36 a 47 anos; e 4 participantes indicaram estar entre os 48 a 55 anos.

A Tabela 1 caracteriza a formação dos respondentes, sendo que pode-se evidenciar que todos os participantes possuem ensino superior completo, e desse total, apenas 3 não ingressaram ou concluíram uma pós-graduação.

Tabela 1. Formação Acadêmica dos participantes

\begin{tabular}{|c|c|}
\hline Descrição da formação acadêmica & Participantes \\
\hline & ------ \% ------ \\
\hline Ensino Superior Incompleto & 0 \\
\hline Ensino Superior Completo & 21,4 \\
\hline $\begin{array}{l}\text { Pós-Graduação Lato Sensu Incompleto } \\
\text { (Especialização; MBA; MBC; MBE) }\end{array}$ & 7,1 \\
\hline $\begin{array}{l}\text { Pós-Graduação Lato Sensu Completo } \\
\text { (Especialização; MBA; MBC; MBE) }\end{array}$ & 42,9 \\
\hline Pós-Graduação Stricto Sensu & \\
\hline Incompleto (Mestrado e Doutorado) & 7,1 \\
\hline $\begin{array}{l}\text { Pós-Graduação Stricto Sensu Completo } \\
\text { (Mestrado e Doutorado) }\end{array}$ & 14,3 \\
\hline Outros & 7,1 \\
\hline
\end{tabular}

Diante desses dados foi possível verificar que os professores e gestores analisados prezam por uma formação contínua, sendo esta de vital importância em um ambiente educacional. Como pontua Nóvoa (1992), a formação continuada tem por objetivo a proposta de discussões teóricas que possibilitem colocar os profissionais em contato com novas metodologias de ensino. Coadunando a afirmação de Nóvoa com o objetivo do trabalho, pode-se afirmar que a formação continuada e a disponibilidade em discutir novas propostas são essenciais para que a abordagem reggiana seja compreendida e posta em prática pelos educadores, contribuindo assim para as mudanças necessárias à melhoria da ação pedagógica. Entretanto, ao mesmo tempo em que deve-se reconhecer a importância no conhecimento de novas teorias como parte do "processo de construção profissional", tem-se que ressaltar que apenas as teorias não bastam por si só. As teorias devem mobilizar as disposições do professor fazendo com que ele as relacionem com seu conhecimento prático, com suas experiências (Nóvoa, 1992). A Tabela 2 caracteriza a formação dos participantes.

Tabela 2. Cargos ocupados pelos participantes

\begin{tabular}{lr}
\hline \multicolumn{1}{c}{ Descrição do cargo ocupado } & Participantes \\
\hline & $-----\%$----- \\
Professor - Pedagogo & 28,6 \\
Professor - Especialista (Artes, Educação & 42,9 \\
Física, Expressão Corporal) & 3,0 \\
Gestor Pedagógico (Coordenador) & 7,1 \\
Gestor administrativo & \\
\hline
\end{tabular}

A Tabela 2 evidencia uma diferença entre a abordagem de Reggio Emilia desenvolvida por Loris Malaguzzi em relação àquela utilizada no colégio analisado, pela presença de professores especialistas. Como ressaltado no começo desse trabalho, a abordagem reggiana tem como destinatário a primeira infância e se caracteriza por um princípio de ensino no qual não existem as disciplinas formais. Todavia no currículo da Educação Infantil da instituição analisada os alunos que vivenciam a abordagem pedagógica postulada por Malaguzzi possuem disciplinas formais, tais como Artes, Educação Física, Expressão Corporal e Música, sendo que tais temas foram abordados de forma integrada no ensino reggiano, não havendo distinção formal entre essas áreas do conhecimento.

$\mathrm{Na}$ Tabela 3 pode-se constatar que todos os participantes da pesquisa estão há mais de 1 ano na instituição, sendo que $50 \%$ desses tem 6 anos ou mais de trabalho. Considerando que a Pedagogia Reggio Emilia foi adotada pela escola desde meados de 2013 e que desde sua adoção a escola tem oferecido cursos de formação a sua equipe docente e gestora, os dados da Tabela 3 revelaram que todos os participantes possuem certa familiaridade com a abordagem que trabalham, supondo-se, desse modo, que todos tenham inserido características da abordagem de Reggio Emilia em suas atividades pedagógicas diárias.

Tabela 3. Tempo que os participantes ocupam seus respectivos cargos

\begin{tabular}{cr}
\hline Tempo de atividade & \multicolumn{2}{c}{ Participantes } \\
\hline- De 1 a 2 & \\
De 4 a 5 & \\
6 ou mais & 7,9 \\
\end{tabular}

A Tabela 4 diz respeito às pedagogias trabalhadas anteriormente pelos participantes, dentre as quais apresentaram-se em maior número o Método Montessoriano $(28,6 \%)$ e a metodologia Sóciointeracionista $(35,7 \%)$. 
Tabela 4. Abordagens pedagógicas já vivenciadas pelos participantes

\begin{tabular}{|c|c|}
\hline Abordagens e Metodologias & Participantes \\
\hline & -------- \% -------- \\
\hline Método Montessoriano & 28,6 \\
\hline Reggio Emilia & 14,3 \\
\hline Método Waldorf & 7,1 \\
\hline Sócio-interacionismo & 35,7 \\
\hline Tradicional & 21,4 \\
\hline Sociocultural & 7,1 \\
\hline Construtivismo & 21,4 \\
\hline Desenvolvimentista & 7,1 \\
\hline Sócio-construtivismo & 7,1 \\
\hline Freinet & 7,1 \\
\hline
\end{tabular}

O Método Montessoriano de acordo com Bózio (2004) é um método que deve ser reconhecido pela busca de respostas para a educação e a vida da criança, partindo das experiências da criança e não das experiências dos adultos. O método Sócio-interacionista, de acordo com Resende (2009), respalda-se no fato de que a interação entre homem e meio é considerada de forma dialética, uma vez que o indivíduo não só internaliza as formas culturais como também intervém e as transforma. Desse modo foi possível observar que ambas as abordagens, assim como a pedagogia reggiana basearam-se no aprendizado como uma construção do conhecimento, a partir das experiências do indivíduo, das suas relações sociais e das relações com o meio no qual está inserido.

Tanto na Metodologia Montessori quanto na Pedagogia Reggio Emilia, as crianças usaram seus sentidos para explorar e direcionar sua experiência educacional. Com Montessori, as crianças têm a liberdade de selecionar atividades pré-preparadas, trabalhar de forma independente e ditar o ritmo. As crianças que trabalham sob a abordagem de Montessori regulam seu próprio ritmo. Eles escolhem os projetos com os quais interagir, quando fazer um lanche, brincar com os outros ou ficar em silêncio. Em um modelo de Reggio Emilia, uma abordagem colaborativa para aprendizagem é tomada e qualquer aluno pode orientar a aprendizagem em sala de aula. Usando suas muitas línguas, as crianças dirigem a curiosidade pessoal e inspiram lições por intermédio do questionamento, resposta e novamente o questionamento, usando o meio ambiente como um educador e ao mesmo tempo seguindo a orientação do professor (Muirhead, 2017).

Quando perguntados a respeito da implementação do PPP e quais foram os envolvidos 10 participantes responderam que houve exclusivamente a participação da equipe gestora e, esses mesmos respondentes declararam ausência de participação dos pais na implementação do PPP. Ainda nessa pergunta, 7 respondentes indicaram que houve participação direta dos professores, seguidos dos outros 7 que ressaltaram que não ocorreu uma participação ativa dos professores no processo de implementação do Projeto.

A partir das respostas obtidas nessa fase da pesquisa, verificou-se que a implementação da abordagem reggiana na instituição de ensino deu-se a partir de decisões e com exclusiva participação da equipe gestora em seu total, havendo participação de pouco mais da metade do número total de professores e nenhuma participação da comunidade. Em uma das falas, um dos respondentes afirmou que houve a realização de cursos e palestras para a implementação dessa metodologia (PARTICIPANTE 6) ${ }^{2}$. Entretanto, como colocado por outro participante da pesquisa, mesmo com a implementação gradual da abordagem e apresentação à comunidade escolar, não há recordação de ter ocorrido uma participação direta dos professores e pais para essa implementação e construção do projeto; tinhamos apenas que conbecê-lo e nos adaptar a ele (PARTICIPANTE 10).

Tendo como base esses relatos foi possível ressaltar que a participação dos professores limitou-se ao conhecimento e adaptação à abordagem e não a partir do diálogo e participação ativa na construção do Projeto Político Pedagógico. A participação da comunidade foi ausente em todo o processo de construção, sendo apenas apresentada à comunidade a "proposta e os passos da implantação” (PARTICIPANTE 3). Para outro respondente, até houve a participação dos professores, mas em relação aos pais, há ainda atualmente um esforço em se trabalhar "a formação deles para compreensão da abordagem através da reflexão das documentações pedagógicas" (PARTICIPANTE 7). Vistos em conjunto, os relatos evidenciaram a ausência da participação da comunidade escolar, com exceção das partes gestoras, no processo de construção da proposta, sendo destinados a esses apenas a sua apresentação, o caminho delineado e o que deveria ser percorrido para a implementação e alcance dos objetivos propostos.

Os dados apresentados pela Tabela 5, expressaram o posicionamento do corpo docente referente à implementação da abordagem de Reggio Emilia no Projeto Político Pedagógico da escola.

Tabela 5. Aceitação do corpo docente

\begin{tabular}{lc}
\hline Descrição & Participantes \\
\hline & $-----\%$----- \\
Plena aceitação do corpo docente. & 40 \\
Aceitação parcial do corpo docente, & 20 \\
marcada por dificuldades e nervosismo. & \\
Aceitação negativa do corpo docente, \\
marcada por dúvidas, grandes dificuldades, \\
resistência e falta de aprofundamento.
\end{tabular}

${ }^{2}$ Os trechos destacados em itálico ao longo do trabalho correspondem às respostas ao questionário aplicado na Instituição pesquisada. Disponibilizamos a transcrição literal das respostas dos questionários a quem interessar e requerer por meio de solicitação no endereço eletrônico do responsável pela pesquisa. 
Os dados obtidos revelaram que a implementação foi conturbada e marcada por dificuldades e resistências por parte dos docentes, sendo que $60 \%$ revelaram enfrentar dificuldades no processo e apenas 40\% afirmaram acreditar em uma plena aceitação referente à implementação da abordagem de Reggio Emilia na escola. Tal fato pode ser constatado na fala de um dos participantes ao afirmar que a maior parte dos professores se mostraram "impressionados e encantados com o projeto", mas ao mesmo tempo demonstraram estar "um pouco preocupados em relação a como seria sua aplicação no dia a dia em sala de aula e na realidade da escola". Todavia, sendo adepto ou não da filosofia de Regio Emilia "todos procuravam se adaptar” (PARTICIPANTE 10).

A tabela 6 mostra a percepção dos pesquisados em relação ao posicionamento da comunidade escolar (pais e alunos) referente à implementação da abordagem de Reggio Emilia no Projeto Político Pedagógico da escola.

Tabela 6. Aceitação da comunidade escolar

\begin{tabular}{|c|c|}
\hline $\begin{array}{l}\text { Descrição quanto a aceitação da } \\
\text { comunidade escolar }\end{array}$ & Participantes \\
\hline & ----- \% ----- \\
\hline $\begin{array}{l}\text { Plena aceitação da comunidade escolar. } \\
\text { Aceitação parcial da comunidade escolar, } \\
\text { marcada por um processo não } \\
\text { consolidado e/ou falta de consciência com } \\
\text { relação à proposta. }\end{array}$ & 60 \\
\hline $\begin{array}{l}\text { Aceitação negativa da comunidade escolar, } \\
\text { marcada por dúvidas, grandes dificuldades } \\
\text { e resistência. }\end{array}$ & 10 \\
\hline
\end{tabular}

As informações coletadas revelaram que especificamente $60 \%$ dos pesquisados afirmaram acreditar em uma plena aceitação do projeto por parte da comunidade escolar. Todavia 30\% dos respondentes sinalizaram que houve uma aceitação parcial apontando a implementação da abordagem como um processo não consolidado ou indicaram que a comunidade escolar possui pouca clareza em relação à proposta. Por fim 10\% afirmaram acreditar em uma aceitação negativa, marcada por dificuldades e resistência com relação à proposta estabelecida. Um professor participante da pesquisa relatou que a aceitação do projeto por parte dos alunos foi realizada em curto espaço de tempo, uma vez que "eles começaram a se adaptar à abordagem, pois fazia parte de sua rotina". Entretanto, o mesmo relato ressaltou que em relação aos pais, a aceitação levou um tempo maior, pois o método utilizado "é muito diferente da cultura deles e do que estão acostumados, ou seja, diferente do que eles entendem por "escola" ou "ensino"”" (PARTICIPANTE 10).

A partir desse relato, pode-se observar dois movimentos de adaptações distintos. Um movimento referente aos alunos que vivenciaram a abordagem diariamente e, dessa forma vagarosamente adentram-se na mesma, e outro com relação aos pais, que vivenciaram a proposta apenas em momentos determinados, imergindo parcialmente nas atividades realizadas pelos alunos.

A tabela 7 ilustra a opinião dos respondentes a respeito da implementação da abordagem reggiana nas atividades pedagógicas diárias.

Tabela 7. Processo de implementação nas atividades pedagógicas diárias

\begin{tabular}{lr}
\hline \multicolumn{1}{c}{$\begin{array}{c}\text { Descrição das atividades pedagógicas } \\
\text { diárias }\end{array}$} & Participantes \\
\hline & ---- \% ----- \\
Não houve dificuldades encontradas. & 21,4 \\
Não foram implementadas mudanças. & 14,3 \\
A dificuldade centra-se na imersão dos & 7,1 \\
alunos na proposta. & 7,1 \\
A mudança centra-se na pratica do & \\
professor e não do conteúdo ministrado. & \\
Implementação de pequenas modificações, \\
marcadas por um processo em continua \\
transformação, resistência e dificuldades, \\
tais como formação adequada, \\
documentos exigidos pela escola, horários, \\
espaço e adequação de currículo. \\
\hline
\end{tabular}

Os dados mostraram que em sua grande maioria $(50,0 \%)$ esse processo foi marcado por pequenas modificações e por uma contínua transformação, permeada por resistência e dificuldades, tais como a falta de uma formação adequada, documentos exigidos pela escola, horários, espaço e adequação de currículo. Devese ressaltar que $14,3 \%$ dos analisados afirmaram não terem implementado modificações em suas atividades e que apenas $21,4 \%$ afirmaram ter implementado modificações sem apresentarem dificuldades.

De acordo com a tabela 7 , as respostas dos participantes da pesquisa contrastaram em relação a esse processo de implementação da abordagem no cotidiano da sala de aula. Para um respondente a adaptação à prática pedagógica foi "efetuada aos poucos, começando com algumas áreas de exploração e registrando a "fala" das crianças para encaixar os conteúdos e habilidades dentro de cada espaço proposto". As grandes dificuldades apontadas foram a "falta de recursos e infraestrutura" (PARTICIPANTE 13). Outro participante ressaltou a dificuldade em conciliar a abordagem com alguns conteúdos, afirmando que ainda há uma dificuldade por parte dos docentes em aplicar a abordagem na prática, uma vez que por mais que se tente encontrar formas de implementação, "ensinar Música segundo a abordagem de Reggio Emilia, ou melhor, ter a prática dela, ainda é muito confuso" (PARTICIPANTE 14).

Os dados apresentados pela Tabela 8 permitiram constatar que os sujeitos analisados, professores (pedagogos); professores especialistas (Artes, Educação 
Física, Expressão Corporal, Música); gestores pedagógicos (coordenadores) e gestores administrativos discordaram em relação a real eficiência da abordagem apresentada, uma vez que, $50 \%$ acreditaram em sua eficácia, enquanto que 50,0\% apresentaram dificuldades que inviabilizaram o alcance pleno do processo de implementação.

Tabela 8. Percepção da aplicabilidade eficaz da abordagem de Reggio Emilia

\begin{tabular}{lc}
\hline \multicolumn{1}{c}{ Descrição da eficácia da abordagem } & Participantes \\
\hline & ----- \% ----- \\
Acredita na eficácia da implementação e & 50,0 \\
atividades diárias da abordagem. & \\
Não acredita na eficácia da implementação & \\
e atividades diárias, apresentando & 50,0 \\
dificuldades tais como, estrutura, relações & \\
sociais, aplicabilidade na realidade escolar. & \\
\hline
\end{tabular}

Os relatos coletados por intermédio dos questionários permitiram vislumbrar essa polarização de opiniões. Para um respondente "há pouco da abordagem sendo aplicada devido a falta de estrutura, muito pela falta de esforço das pessoas envolvidas e parte por falta de uma unidade da equipe de liderança" (PARTICIPANTE 5). Entretanto, para outro participante, a abordagem Reggio Emilia "nasce de uma realidade, de um momento histórico único. $\mathrm{O}$ movimento de implementação parte da desconstrução de uma trajetória educacional para reconstruir uma educação inspirada em Reggio, a qual muitos de nós conhecemos apenas de relatos, fatos, estudos e foto" (PARTICIPANTE 7).

Um respondente ressaltou a presença nesse processo de implementação de "questões culturais embutidas, muitas vezes o convencimento e conhecimento da família, são uns dos fatores mais difíceis". Contudo, "quando os pais se apropriam do processo de desenvolvimento e vivenciam junto com as crianças, começam entender a necessidade da exploração" (PARTICIPANTE 12). Somado a isso, em observação direta do ambiente de ensino, um relato sobressaiu-se. Segundo um participante constituinte da parte gestora pedagógica a "abordagem iniciou há quatro anos, todavia não acredito ser uma implementação! Acredito que o que temos é uma inspiração!”

A tabela 9 reúne alguns fatores elencados pelos pesquisados que poderiam auxiliar em um maior envolvimento e aplicabilidade da abordagem de Reggio Emilia.

Um dos respondentes ressaltou que "uma maior abertura da gestão do colégio com relação ao diálogo com o corpo docente, afim de entender as reais dificuldades e especificidades encontradas" seria um fator preponderante para o sucesso da implementação da abordagem no Colégio analisado. Somado a isso, apontou para a necessidade de "uma formação adequada da equipe gestora e docente com relação a esta abordagem, uma vez que, possui características singulares. Por fim, o participante ressaltou que é imperativo para o êxito do processo uma abertura da comunidade escolar (famílias) com relação aos principais objetivos da abordagem, uma vez que, esta caminha para diferentes percursos do ensino tradicional brasileiro" (PARTICIPANTE 6).

Tabela 9. Fatores facilitadores para um maior envolvimento e aplicabilidade das propostas vinculadas a abordagem de Reggio Emilia

\begin{tabular}{|c|c|}
\hline Descrição & Participantes \\
\hline & ---- \% ----- \\
\hline $\begin{array}{l}\text { Possibilitar e aumentar o diálogo entre a } \\
\text { comunidade escolar, maior flexibilidade da } \\
\text { equipe gestora, maior envolvimento das } \\
\text { famílias, incentivar o diálogo entre a } \\
\text { equipe docente. }\end{array}$ & 64,3 \\
\hline $\begin{array}{l}\text { Visitar outras escolas que trabalhem a } \\
\text { mesma abordagem pedagógica, visando } \\
\text { experiência e troca de saberes. } \\
\text { Adaptação da abordagem de Reggio }\end{array}$ & 7,1 \\
\hline $\begin{array}{l}\text { Emilia a realidade escolar, levando em } \\
\text { consideração fatores socioculturais. }\end{array}$ & 21,4 \\
\hline $\begin{array}{l}\text { Formação adequada da equipe gestora e } \\
\text { docente. }\end{array}$ & 57,1 \\
\hline
\end{tabular}

Os dados coletados refletiram um fragmento do processo de implementação da Pedagogia de Reggio Emilia no colégio analisado, todavia revelaram características, questionamentos e consequências importantes no processo de implementação de novas pedagogias. As mudanças implementadas no Projeto Politico Pedagógico, ainda que exploradas ao nível da gestão escolar, ainda estão em constante transformação e adaptação no âmbito das atividades pedagógicas desenvolvidas no cotidiano da comunidade escolar.

\section{Conclusão}

Os dados coletados durante a pesquisa permitem concluir que não há uma participação concreta e ativa da comunidade escolar na elaboração do Projeto Político Pedagógico da escola analisada, evidenciando um fator que conflitua com a pedagogia Reggio Emilia, elencada como abordagem pedagógica fundamental da qual se extrai os métodos de ensino utilizados na instituição pesquisada.

Ainda que se considere que o PPP investigado encontra-se em processo de estruturação, é possível visualizar que as decisões e ações realizadas para a sua implementação não ocorreram de forma coletiva, mas sim de forma centralizadora, tendo como núcleo os gestores pedagógicos e administrativos, tornando-se desse modo contrário ao pensamento democrático e coletivo característico da abordagem reggiana. Esse fator revela que o processo de implementação e 
desenvolvimento da abordagem, caminha numa direção contrária à experiência das escolas reggianas, na Itália, uma vez que essas partem de um grande envolvimento com a comunidade local.

Pode-se concluir a partir dos dados estudados, que um dos obstáculos presentes para uma construção coletiva do PPP e para a efetivação da implantação da abordagem reggiana, seja a carência de espaços de diálogo, reflexão, elaboração e acompanhamento desse documento por todos os atores envolvidos no processo de ensino.

Deve-se ressaltar a singularidade da proposta do Colégio analisado em se integrar a uma abordagem diferente das que muitos colégios adotam, este fator por si só, apresenta-se como um verdadeiro desafio na construção de um Projeto Político Pedagógico. Deve-se ressaltar que a construção do PPP em qualquer instituição de ensino e independente da abordagem pedagógica escolhida como norteadora apresenta-se como um percurso complexo, pois implica barreiras pessoais e coletivas, sendo de vital importância para seu êxito, uma equipe estruturada, engajada e embasada teoricamente, que proporcione uma gestão democrática e crie canais de diálogo e participação de toda a comunidade escolar.

Os dados coletados apontam para a dificuldade apresentada na implementação do PPP norteado pela abordagem pedagógica de Reggio Emillia e para a ausência da participação da comunidade nesse processo. Por meio dessa informação, pode-se concluir que as principais dificuldades em se implementar de maneira efetiva essa proposta estão, em grande parte, relacionadas à ausência da participação direta de pais e professores na elaboração do PPP e pelo fato de que os atores educacionais e a comunidade escolar foram inseridos num momento posterior a construção do PPP.

Diante dessas evidências, conclui-se que a participação da comunidade escolar na construção do Projeto Político Pedagógico nesta unidade de ensino encontra-se frágil, acarretando uma construção instável do Projeto, uma vez que, para que ocorra uma real participação efetiva e democrática nessa construção, a escola obrigatoriamente deve oferecer, de forma contínua, espaços de diálogos, reflexões e convivência social, envolvendo toda a comunidade escolar.

Desse modo, como possíveis soluções para a resolução das contradições encontradas, pode citar uma melhor capacitação da equipe gestora e docente com relação à abordagem reggiana; proporcionar maiores espaços de diálogos, reflexões e convivência social, envolvendo toda a comunidade escolar e a adaptação da abordagem de Reggio Emilia a realidade escolar, levando em consideração fatores socioculturais.

Por fim deve-se ressaltar que a participação de todos os envolvidos no processo escolar deve transpor o conceito de integração dos envolvidos na escola, devemos entendê-la como uma participação política democrática, formulada pelo e por intermédio do trabalho coletivo e da ação conjunta.

\section{Referências}

Alves-Mazzotti, A.J. 2006. Usos e abusos dos estudos de caso. Cadernos de Pesquisa 36: 637-651.

Bózio, E.R. 2004. Software de Treinamento e de Divulgação do Método Montessori. CD-ROM.

Conti, C. 2018. Reggio Emilia: uma escola feita no pós-guerra. Disponível em: <http://educacaoparapaz.com.br/reggioemilia-uma-escola-feita-no-pos-guerra/>. Acesso em: 20 fev. 2018.

Ferrari, G.V. 2011. A importância do coletivo na construção do Projeto Político Pedagógico da instituição escolar. Perspectiva, Erechim 35(132): 159-170.

Godoy, A.S. 1995. Introdução à pesquisa qualitativa e suas possibilidades. Revista de Administração de Empresas 35(2): 57-63.

Latalisa, A. 2010. Um olhar sobre a abordagem educacional de Reggio Emilia. Paidéia 8: 55-80.

Lima, L. 2002. Organização escolar e democracia radical: Paulo Freire e a governação democrática da escola pública. Cortez, São Paulo, SP, Brasil.

Maanen, J.V. 1979. Reclaiming qualitative methods for organizational research: a preface. Administrative Science Quarterly 24(4): 520-526.

Malaguzzi, L. 1999. História, idéias e filosofia básica. In: Edwards, C.; Gandini, L.; Forman, G. 1999. As cem linguagens da criança: a abordagem de Reggio Emilia na educação da primeira infância. Tradução de Dayse Batista. Artes Médicas, Porto Alegre, RS, Brasil.

Mizukami, M.G.N. 1986. Ensino: as abordagens do processo. EPU, São Paulo, SP, Brasil.

Muirhead, R. 2017. Reggio Emilia vs. Montessori: which is right for your child? Disponível em: < https://www.goodwin. edu/enews/reggio-emilia-vs-montessori/>. Acesso em: 19 fev. 2018

Neves, J.L. 1996. Pesquisa qualitativa: características, usos e possibilidades. Caderno de Pesquisas em Administração 1(3): 103-113.

Nóvoa, A. 1992. Os professores e a sua formação. Publicações Dom Quixote, Lisboa, Portugal.

Resende, M.L.M. 2009. Vygotsky: um olhar sociointeracionista do desenvolvimento da língua escrita. Disponível em: <http:// www.psicopedagogia.com.br/index.php/979-vygotsky-umolhar-socio-interacionista-do-desenvolvimento-da-linguaescrita>. Acesso em: 09 jun. 2017.

Rinaldi, C. 1999. O currículo emergente e o construtivismo social. In: Edwards, C.; Gandini, L.; Forman, G. 1999. As cem linguagens da criança: a abordagem de Reggio Emilia na educação da primeira infância. Tradução de Dayse Batista. Artes Médicas, Porto Alegre, RS, Brasil.

Veiga, I.P.A. 2004. Educação Básica e Educação Superior: Projeto político Pedágógico. Papirus, Campinas, SP, Brasil. 